\title{
NARRAÇÃO ESPORTIVA DE FUTEBOL NO RÁDIO: ENTRE CONVENÇÕES E INTENÇÕES
}

\author{
SOCCER NARRATIVE ON THE RADIO: BETWEEN CONVENTIONS AND INTENTIONS \\ NARRACIÓN DEPORTIVA DE FÚTBOL EN LA RADIO: ENTRE CONVENCIONES E INTENCIONES \\ Cristiane Alvarenga Rocha Santos* \\ Pontifícia Universidade Católica de Minas Gerais - PUC-Minas, Belo Horizonte, BR
}

\begin{abstract}
RESUMO: Considerando as discussões no âmbito da Pragmática acerca dos atos de fala, abordamos, no presente artigo, alguns aspectos que nos permitem identificar um ato realizado por um sujeito como apresentando um significado de origem convencional ou de origem intencional. Para tanto, fazemos, inicialmente, uma breve explanação sobre a noção de "força ilocucional" (SEARLE, 1986; VANDERVEKEN, 1985; MARI, 2001, 2011) e, a seguir, sobre as noções de "convencionalidade" e "intencionalidade" (SEARLE, 1995; RÉCANATI, 1986; VANDERVEKEN, 1993). Em um momento posterior, discutimos como uma análise dos atos indiretos a partir das máximas conversacionais de Grice pode colaborar para a compreensão de tais atos na sua dimensão intencional (VANDERVEKEN, 1993). Por fim, apresentamos as noções de "convenções de uso" e "convenções de linguagem" (MORGAN, 1991) a fim de discutir em que extensão os atos indiretos se submetem a uma ou a outra em determinadas situações enunciativas.
\end{abstract}

PALAVRAS-CHAVE: narração esportiva; futebol; atos de fala; rádio.

ABSTRACT: Considering the discussions on the pragmatics of speech acts, we discuss in this article some aspects that allow us to identify an act performed by a subject as having a meaning of conventional origin or intentional source. To this end, we will perform an initial brief explanation of the notion of "illocutionary force" (SEARLE, 1986; VANDERVEKEN, 1985; MARI, 2001, 2011), and then, on the notions of "conventionality" and "intentionality" (SEARLE, 1995; RÉCANATI, 1986; VANDERVEKEN, 1993). At a later time, we will discuss how an analysis of indirect acts from Grice's conversational maxims can contribute to the understanding of such intentional acts of their size (VANDERVEKEN, 1993). Finally, we will introduce the notions of "conventions of usage" and "conventions of language" (MORGAN, 1991) to discuss the extent to which indirect acts undergo one or another in specific enunciative situations.

KEYWORDS: sport narrative; soccer; speech acts; radio.

RESUMEN: Partiendo de la consideración de discusiones desencadenadas en el ámbito de la Pragmática acerca de los actos del habla, se aborda, en este artículo, algunos aspectos que nos permiten identificar un acto realizado por un sujeto que presenta un significado de origen convencional o de origen intencional. Para tanto, primeramente, presentamos una breve explicación acerca de la noción de "fuerza ilocutiva" (SEARLE, 1986; VANDERVEKEN, 1985; MARI, 2001, 2011) y, a continuación, acerca de las nociones de "convencionalidad" e "intencionalidad" (SEARLE, 1995; RÉCANATI, 1986; VANDERVEKEN, 1993). En un momento posterior, discutimos como un análisis de los actos indirectos a partir de las máximas conversacionales de Grice puede contribuir para la comprensión de dichos actos de habla en su dimensión intencional (VANDERVEKEN, 1993). Por fin, presentamos las nociones de "convenciones de uso" y "convenciones de lenguaje" (MORGAN, 1991), con el propósito de discutir en qué medida los actos indirectos se subordinan a una o a otra en determinadas situaciones enunciativas.

PALABRAS-CLAVE: narración deportiva; fútbol; actos de habla; radio.

\section{INTRODUÇÃO}

A Teoria dos Atos de Fala, proposta por Austin em 1962, passou por diversos desdobramentos ao longo do tempo, dentre os quais se destacam os trabalhos de Searle (1995). Os trabalhos desse autor são vistos por alguns como uma continuidade ao que seu precursor desenvolveu, porém como uma leitura distinta da que Austin propunha em seus textos. A despeito dessas divergências quanto às interpretações de seu discípulo, acreditamos que muitas das ideias que Austin defendeu em seus textos colaboraram, de alguma forma, para o desenvolvimento da teoria.

Assim, a obra produzida por Searle (1995), embora não seja livre de lacunas, apresenta uma grande importância em termos do estudo da força ilocucional e do tratamento dos atos indiretos e da intencionalidade. Essa relevância pode ser verificada nos trabalhos de Vanderveken (1985) e Morgan 
(1991), os quais, para nós, têm contribuído para uma melhor compreensão dos fatos apresentados por Searle.

Quanto às narrativas esportivas de futebol, consideramo-las uma prática discursiva que faz parte do nosso cotidiano enquanto seres sociais. Podemos observar, na troca verbal complexa empreendida pelos interlocutores, a recorrência a diversos tipos de atos de fala que se realizam, na maioria das vezes, em conformidade com a função discursiva desempenhada por esses participantes em uma enunciação determinada.

Tendo em vista o espaço que o rádio ainda ocupa em nossa sociedade, apesar do advento da televisão e da internet, principalmente quando se trata de transmissões de partidas de futebol, e os poucos estudos dessa interface linguagem/esporte, sob um viés discursivo, propomo-nos a analisar os atos de fala presentes em narrativas esportivas de futebol transmitidas pela Rádio Globo e pela Rádio Eldorado ESPN, a partir da noção de "força ilocucional"; apontar a recorrência de atos convencionais e intencionais nessas situações comunicativas ${ }^{1}$; apresentar, com base na noção de "força ilocucional", uma análise dos atos indiretos na dimensão das convenções e das intenções; analisar os atos indiretos em relação às máximas conversacionais de Grice; observar em que extensão os atos indiretos analisados obedecem a "convenções de uso"; e investigar, inicialmente, algumas implicações para a produção e compreensão do discurso, caso haja predominância de um ou outro tipo de ato (convencional ou intencional).

\section{ASPECTOS GERAIS DA TEORIA DOS ATOS DE FALA: UMA TIPOLOGIA DOS ATOS}

Austin, quando propôs sua Teoria dos Atos de Fala em 1962, enfatizou o estudo dos atos de fala performativos, os quais se opunham aos constatativos, porque nada descreviam, nada relatavam. Mais tarde, passou, então, a diferenciar os atos em três tipos, que consistem em três dimensões de um mesmo ato de fala: locucionários (ato de dizer algo; subdividido em ato fonético, fático e rético), ilocucionários (ato ao dizer algo) e perlocucionários (atos que produzimos porque dizemos algo).

Os atos locucionários constituíam-se como base para qualquer proferimento, enquanto aos demais cabia uma distinção: “[...] podemos ter esperança de isolar o ato ilocucionário do ato perlocucionário, na medida em que este produz consequências e o outro não é, em si mesmo, uma 'consequência' do ato locucionário." (AUSTIN, 1990, p. 99). Segundo Austin, os atos ilocucionários podem estar relacionados com a produção de certos efeitos - "o efeito equivale a tornar compreensível o significado e a força da locução. Assim, a realização de um ato ilocucionário envolve assegurar sua apreensão" (AUSTIN, 1990, p. 99, grifo nosso) e levar, devido a uma convenção, a uma resposta ou sequela que pode ter uma ou duas direções. Enquanto isso, alguns atos perlocucionários, que não possuem fórmula ilocucionária, sempre têm sequelas. Além disso, a resposta ou sequela de um ato perlocucionário pode advir adicionalmente ou inteiramente por meio de um ato não locucionário.

Dessa forma, Austin (1990, p. 101) conclui que “[...] podemos conseguir algumas sequelas de atos perlocucionários por meios inteiramente não convencionais [...]”, porém,

[...] não pode haver um ato ilocucionário a menos que os meios utilizados sejam convencionais, e portanto os meios para alcançar os fins de um ato desse tipo em forma não verbal têm de ser convencionais. (AUSTIN, 1990, p. 101)

Voltaremos mais adiante à questão da convencionalidade e da intencionalidade na produção de um ato de fala. Por enquanto, gostaríamos de destacar os avanços da teoria promovidos por Searle, o qual contribuiu para uma nova visão de ambos os conceitos, a partir do destaque dado à noção de força ilocucional.

\subsection{Dos constatativos e performativos à força ilocucional}

Após muitas críticas positivas e negativas ao enfoque dado por Austin aos performativos em contraste com os constatativos, ele dedicou-se ao estudo da força ilocucional. Esse conceito foi retomado por Searle (1995), passando a adquirir o papel de fundamento da teoria.

${ }^{1}$ Parte deste trabalho já foi discutida em Santos (2010). Os resultados serão tomados como ponto de partida para a investigação aqui tratada. 
Searle (1995) verificou algumas necessidades na teoria como: de formular uma metalinguagem mais sistematizada do que foi discutido por seu antecessor, Austin; de aplicar às reflexões desse autor um padrão estrutural, integrando as partes que compõem sua teoria; e de apresentar uma abordagem mais abrangente, que não levasse em conta apenas atos performativos explícitos produzidos em situações protocolares ou ritualísticas, mas qualquer ato socialmente reconhecido. Segundo Mari (2001, p. 106), tudo isso foi possível "[...] devido à retomada de aspectos da construção do sentido de uma proposição e de suas implicações diretas no desempenho de uma ação:”.

Observamos que Searle (1995) imprime um caráter universal à análise dos atos, já que toda forma de linguagem, segundo ele, está comprometida com um tipo de ação. A força ilocucional, então, define como um locutor age sobre o(s) seu(s) alocutário(s) ou sobre a realidade. Com base nisso, é possível retomar o que o pesquisador denominou "direções de ajuste/ajustamento" na relação linguagem (palavra)/realidade (mundo), as quais engendram os pontos de realização dos atos de fala.

\begin{tabular}{|l|l|l|l|}
\hline \multicolumn{4}{|c|}{ Direções de ajustamento } \\
\hline \multicolumn{1}{|c|}{$\mathrm{P} \rightarrow \mathrm{M}$} & \multicolumn{1}{|c|}{$\mathrm{M} \rightarrow \mathrm{P}$} & \multicolumn{1}{c|}{$\mathrm{P} \leftrightarrow \mathrm{M}$} & \multicolumn{1}{c|}{ Direção Ø } \\
\hline $\begin{array}{l}\text { - P ajusta-se a um } \\
\text { estado de coisas } \\
\text { existente de forma } \\
\text { independente da } \\
\text { enunciação utilizada } \\
\text { para representá-lo. } \\
\text { - Estado de coisas: pré- } \\
\text { existe ao ato de } \\
\text { enunciação. } \\
\text {-Linguagem: se orienta } \\
\text { para as ações. }\end{array}$ & $\begin{array}{l}\text { - Estado de coisas é } \\
\text { criado/modificado } \\
\text { pela ação de P de } \\
\text { uma enunciação. } \\
\text { - Estado de coisas: } \\
\text { alterado de modo a } \\
\text { adequar-se a P. }\end{array}$ & $\begin{array}{l}\text { - Estado de coisas de } \\
\text { um mundo possível } \\
\text { é alterado para se } \\
\text { ajustar a P, da mesma } \\
\text { forma que P } \\
\text { representa } \\
\text { o mundo como já } \\
\text { estando assim alterado } \\
\text { na perspectiva do } \\
\text { seu locutor. }\end{array}$ & $\begin{array}{l}\text { em questão } \\
\text { dúvidas quanto à } \\
\text { satisfação ou } \\
\text { não entre P e o } \\
\text { estado de coisas } \\
\text { representado. } \\
\text { - A verdade do } \\
\text { estado de coisas é } \\
\text { pressuposta pelos } \\
\text { interlocutores que } \\
\text { participam do ato. }\end{array}$ \\
\hline П: assertivo & $\begin{array}{l}\text { П: comissivo, } \\
\text { diretivo }\end{array}$ & П: declarativo & П: expressivo \\
\hline
\end{tabular}

Quadro 1 - Direções de Ajustamento. Fonte: Mari (2011).

Uma força ilocucional, como um elemento que define a forma de um proferimento apresenta a forma $\mathrm{F}(\mathrm{p})$, e é constituída por cinco componentes: ponto de realização $(\pi)$, modo de realização $(\mu)$, condições de conteúdo proposicional $(\Theta)$, condições preparatórias $(\Sigma)$, e condições de sinceridade $(\Psi)$. Abordaremos brevemente cada um deles.

\begin{tabular}{|l|}
\hline \multicolumn{1}{|c|}{ Componentes de uma força ilocucional } \\
\hline Ponto de realização: $\pi$ \\
\hline - Conjunto de todas as proposições associadas aos contextos possíveis para sua realização; \\
- Representa o que o locutor pretende realizar com seu proferimento; \\
- Dois enfoques alternativos: no estado de coisas (assertivo, expressivo) \\
nos interlocutores (diretivo, comissivo)
\end{tabular}


- Atuam como base de sustentação, se valendo de pressupostos que assegurem legitimidade a forças desempenhadas adequadamente;

$\mu$ : papel decisivo na sua especificação, quando avaliamos o seu efeito na realização de um ato;

- Só podem ser supostas quando associadas à sua realização específica, em razão dos componentes que o definem como um ato particular.

Condições de sinceridade: $\Psi$

- Atitudes proposicionais que expressam estados mentais no momento da execução de um ato. Cada estado mental caracteriza-se por modalidades que incorporam intenções de que o locutor realize algo ou desejos do próprio locutor em fazê-lo;

- Raramente identificadas por um marcador linguístico;

- Trazem, para a troca verbal, uma dimensão ético-moral, a qual se supõe como um fundamento básico nas práticas de linguagem;

- Também só podem ser supostas quando associadas à sua realização específica, em razão dos componentes que o definem como um ato particular.

Quadro 2 - Componentes de uma força ilocucional: Fonte: Mari (2011).

Ao se preocupar com a questão da significação na produção e recepção dos atos de fala, Searle (1995) cedeu um grande espaço de sua pesquisa ao estudo dos atos indiretos que, diferente dos atos diretos, são ancorados nas intenções do falante e, por isso, a força ilocucionária, neste caso, apresenta uma dupla realização. Trataremos dessa particularidade dos atos indiretos no próximo tópico.

Vanderveken (1985), por sua vez, tem contribuído igualmente para o desenvolvimento da teoria dos atos de fala, promovendo uma aproximação entre esta e a Teoria da Conversação, assim como o fez Searle (1995, p.173), pois, segundo ele, “[ [..] os atos ilocucionais são as unidades constitutivas da conversação". Sua proposta também colabora para a compreensão dos chamados "atos não literais" ou "indiretos", já que

[…] os vários princípios conversacionais necessários à compreensão dos atos de fala indiretos e das implicaturas conversacionais se aplicam aos atos ilocucionais de todos os tipos (e não só às asserções) e devem, consequentemente, ser formulados para dar conta das enunciações com qualquer possível força ilocucional. (VANDERVEKEN, 1985, p. 174)

Abordaremos as perspectivas de ambos os pesquisadores com mais detalhes no item a seguir.

\subsection{Convencionalidade $x$ Intencionalidade}

Austin (1990), ao anular a distinção entre enunciados constatativos e performativos, num segundo momento de sua teoria, passou a afirmar também que os atos realizados por meio de enunciados performativos seriam atos convencionais. Dessa forma, ele propôs uma diferenciação entre ações que seriam naturais e ações convencionais. As primeiras se realizariam a partir de atos fonéticos, ou seja, proferimentos de uma ou mais sequências de fones, e que necessitam ser congregados por um sistema para que apresentem um significado. As últimas caracterizam-se como atos fáticos e réticos, e fazem parte da enunciação de um enunciado, associando sentido e referente conforme a situação. Assim, como diz Mari (2011), as ações convencionais compõem um conjunto de convenções que integram um sistema e permitem a existência de objetos socialmente aceitos.

No desenvolvimento da teoria, Searle (1995) afirma a existência de dois tipos de fatos: brutos e institucionais. Aqueles decorrem de um conjunto de ações que compõem um fato qualquer como um batismo, um julgamento, uma cerimônia de posse e, como tal, não implicam isoladamente uma convenção. No entanto, para os analisarmos como fatos institucionais, é necessário considerar que o conjunto de proferimentos que realizam um ato de batizar, julgar, empossar implica um sistema de convenções que os tornem atos institucionais.

Mari (2001) lembra que tais atos, resultantes de fatos institucionais e, portanto, institucionais também, apresentam padrões e normas cristalizados, pré-estabelecidos, que permitem aos interlocutores relacionálos a determinados propósitos comunicativos, ou seja, são convencionalizados. Porém, existem atos

[...] com graus de exigências menos rígidos e costumam delinear aspectos do seu uso convencional em razão de fatores que se correlacionam com a identidade dos locutores integrantes da relação - ordem $\mathrm{x}$ pedido -, das condições formais do proferimento - juramento $\mathrm{x}$ asserção -, da natureza das ações a serem realizadas - promessa x ameaça. (MARI, 2001, p. 82) 
Aqui é importante remetermos à problemática da necessidade de existirem marcas exteriores que permitem o reconhecimento de uma força ilocucional. De acordo com Récanati (1981), os atos convencionais se dividem entre aqueles que têm a existência assegurada no interior de uma instituição qualquer e aqueles que têm a existência regulada por uma instituição que relaciona o significado a um ato. Estes últimos ainda podem se dividir em: convencionalismo radical forte - "[...] que faz com que um locutor realize um ato A é hoje uma convenção que associa esse ato a uma forma linguística particular que o locutor emprega [...]” (RÉCANATI, 1981, p. 97, tradução nossa) - e convencionalismo radical fraco:

[...] repousa sobre a tese segundo a qual um ato ilocucionário existe se há um meio convencional de realizá-lo - uma fórmula ou um indicador tendo apenas por função assinalar sua realização -, mesmo se o emprego desse procedimento convencional não o requer para realizar o ato. (RÉCANATI, 1981, p. 97, tradução nossa, grifo nosso)

É complicado tomarmos qualquer uma dessas posições como a mais correta. Por isso, concordamos com Mari (2001, p. 83) que "[...] a única convenção que tem valor universal, na realização de um ato, é aquela representada pela natureza semântica da proposição que serve de base para o ato". Assim, segundo o autor, um enunciado como "Devagar!", em uma sinalização na estrada, pode ter a força ilocucional de uma sugestão, de uma advertência ou de um aviso, mas a força diretiva sempre terá, independente do modo em que se realiza, o significado "baixa velocidade". Analisando outro exemplo como "O placar ainda está zero a zero", Mari (2001) afirma que, pelas convenções linguísticas, ele não significa nada além de que não se registra vantagem para nenhum dos integrantes de uma disputa, porém, quando realizamos este ato indiretamente, ele pode descrever diversos estados de coisas que podem não remeter diretamente a uma disputa esportiva, mas a um momento de um relacionamento amoroso, uma negociação, entre outros.

Quanto à dimensão da intencionalidade, defenderemos que ela justifica a esfera perlocucional de um ato de fala e, além disso, faz parte da força ilocucional de um ato de fala indireto. Isso conduz a seguinte lógica:

Se, de acordo com Strawson, recorrendo a Grice, a intenção presente em um ato afeta principalmente o modo pelo qual o locutor significa o conteúdo proposicional - o locutor significa não-naturalmente ao proferir um ato -, é possível supor que a realização de um ato indireto venha implicar, de forma decisiva, a presença de intenções. (MARI, 2001, p. 84).

Considerando a instância de recepção, é importante ressaltar que apenas a situação enunciativa e certos elementos que a constituem, como os aspectos prosódicos, nos permitirão interpretar uma pergunta como um pedido, uma asserção como uma ordem ou um pedido, por exemplo, pois, embora a intenção faça parte da força ilocucional, significando P, ela dificilmente será marcada linguisticamente no ato proferido. Austin (1990, p. 92) apresenta dois modos por meio dos quais a relação locutor (Loc) e alocutário (Aloc) pode se configurar em termos das intenções, aos quais Mari (2011) acrescenta mais três possibilidades:

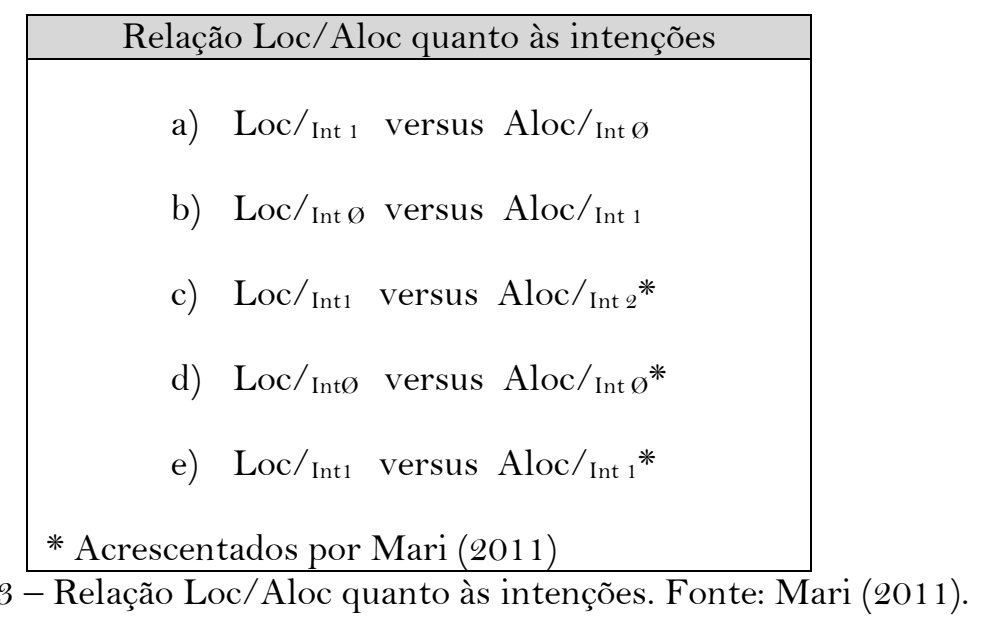

Nesse esquema, observamos que, embora o locutor seja dotado de uma intenção, a qual pretende imprimir ao seu enunciado, ele depende do alocutário para que essa intenção seja percebida ou não e, consequentemente, compreendida por ele, gerando uma resposta ou sequela. Esse fato demonstra o terreno "movediço" em que se instauram os atos produzidos no domínio da intencionalidade. Caracterizado como 
instável e não demarcado na superfície dos atos, o que se pretende nessa dimensão é criar um significado não natural.

Assim, percebemos que há padrões diferentes que determinam ambos os domínios, sendo que, no domínio das convenções, há um padrão de certeza, de verificação maior do que no das intenções. Vejamos agora como a noção de "atos indiretos" é tratada na perspectiva de Searle (1995) e de Vanderveken (1993).

\section{OS ATOS INDIRETOS NA PERSPECTIVA DE SEARLE E DE VANDERVEKEN}

Searle (1995) apresentou grande contribuição à Teoria dos Atos de Fala ao propor uma discussão mais aprofundada, embora ainda com alguns problemas, acerca dos atos de fala indiretos. Podemos considerar que eles se inserem em casos mais complexos de significação, ao contrário de atos que significam o que o locutor quer significar literalmente ao emitir um proferimento. Nesses casos, o locutor tenciona produzir um efeito ilocucionário no seu alocutário, a fim de fazer com que este reconheça essa sua intenção em produzi-lo, além disso, ele tenciona que esse reconhecimento seja realizado em função do conhecimento que o alocutário tem das regras que regem a produção de uma sentença.

Nos atos de fala indiretos, o que vemos é o falante emitir uma sentença, querendo significar o que diz, mas também desejando significar algo mais. Desse modo, esses atos apresentam duas forças ilocucionais, já que eles realizam dois atos ilocucionários em uma só sentença. Por isso, ao analisarmos um ato como esse, a descrição da força ilocucionária variará, como veremos mais adiante.

A hipótese que desejo defender é simplesmente esta: em atos de fala indiretos, o falante comunica ao ouvinte mais do que realmente diz, contando com a informação de base, lingüística [sic] e não linguística [sic], que compartilhariam, e também com as capacidades gerais de racionalidade e inferência que teria o ouvinte. (SEARLE, 1995, p. 50)

Essa hipótese de Searle parece se relacionar ao que ele diz mais adiante em seu livro "Expressão e Significado", de que o problema em relação aos atos indiretos se assemelha a um problema da análise epistemológica da percepção, pois depende da compreensão da forma pela qual um alocutário ou ouvinte percebe e se apropria do que o locutor ou falante diz. É um fenômeno que vai além da significação da sentença, que envolve muitos outros aspectos, já que esses atos são produzidos a partir de um domínio intencional do locutor. "O que se acrescenta nos casos indiretos não é nenhum significado sentencial diferente ou adicional, mas um significado adicional do falante." (SEARLE, 1995, p. 70). Morgan (1991) também concorda com Searle, ao tentar responder a questão "Como as pessoas entendem o que é dito a elas?":

[...] nossa capacidade de inferir alguma forma quais eram as intenções do falante ao dizer que ele disse, com o significado literal que ele tem. Mas essa habilidade não é, em geral, uma habilidade estritamente lingüística [sic] [...], mas a aplicação aos problemas lingüísticos [sic] de estratégias gerais de senso comum para inferir intenções por trás de todos os tipos de atos, que podem ou não ser diferentes em culturas diferentes. (MORGAN, 1991, p. 244, tradução nossa)

Searle (1995), assim como Vanderveken (1993) e Morgan (1991), propõe como aparato teórico para tentar explicar os atos indiretos uma junção entre a teoria dos atos de fala e os princípios gerais de conversação cooperativa de Grice (1982), além de levar em consideração a informação factual prévia compartilhada pelos interlocutores e a habilidade do alocutário/ouvinte de fazer inferências. Com isso, Searle parece enfocar em seus trabalhos uma perspectiva mais interativa do funcionamento da linguagem, em comparação ao que foi desenvolvido por Austin (1990).

Para entendermos melhor como os princípios de cooperação de Grice (1982) podem ser articulados à teoria dos atos de fala, recorreremos à Vanderveken para quem

[…] até agora não houve muito processo no desenvolvimento de uma teoria Pragmática capaz de construir o significado dos falantes nos enunciados não literais. Searle e Grice tiveram sua contribuição, explorando a idéia [sic] de que o uso da linguagem é governado por certas máximas das quais o falante depende a fim de fazer o ouvinte entender seus enunciados não literais. Mas sua análise informal do significado do falante permaneceu amplamente heurística e parcial, e com uma lacuna de um conteúdo teórico preciso. (VANDERVEKEN, 1993, p. 331, tradução nossa). 
Não nos deteremos à crítica do autor, pois aqui nos interessa apontar de qual lugar ele enuncia ao discutir os atos indiretos e o que ele apresentou de novo à teoria dos atos de fala.

Assim, segundo Vanderveken (1993), os atos ilocucionários se submetem a condições de sucesso, de realização não defectiva e a condições de satisfação. As condições de sucesso são "[...] as condições que se deve obter em um contexto de enunciação possível a fim de que o falante prossiga em realizar esse ato nesse contexto." (VANDERVEKEN, 1993, p. 373, tradução nossa). Elas são determinadas pelas componentes da força ilocucional e pelo conteúdo proposicional $(\mathrm{P})$. Quanto à realização não defectiva, um ato ilocucionário só pode ter tal caráter no contexto enunciativo se e somente se ele, as suas condições preparatórias e de sinceridade forem realizados com sucesso nesse contexto. As condições de satisfação são baseadas na noção de correspondência entre linguagem e mundo. Por isso,

[...] quando um ato ilocucionário de forma $\mathrm{F}(\mathrm{P})$ é satisfeito no contexto de enunciação, há um sucesso no ajuste entre a linguagem e o mundo, e o conteúdo proposicional $\mathrm{P}$ é verdadeiro nesse contexto porque ele corresponde a um estado de coisas existente. (VANDERVEKEN, 1993, p. 374, tradução nossa).

As principais máximas de Grice (1982), baseadas em categorias kantianas, são: a máxima da quantidade (diz respeito à quantidade de informação que o falante oferece ao outro. Espera-se que sua contribuição seja informativa o suficiente para o que está sendo tratado, e não mais do que o esperado); a máxima da qualidade (orienta o indivíduo a afirmar somente aquilo que for verdade. Assim, ele não deve informar o que acredita ser falso e não informar nada que não possa fornecer provas ou evidências suficientes); a máxima do modo (diz respeito ao modo como esse conteúdo é expresso. Assim, o falante deve ser claro, evitando obscuridade, ambiguidade, prolixidade e desordem); e a máxima da relação ou relevância (o falante deve dizer apenas o que for relevante em determinada situação comunicativa). Essas máximas governam a conversação e, portanto, devem ser respeitadas por falante e ouvinte se desejarem alcançar sucesso e se fazer compreender nessa troca verbal. O falante conta com a habilidade do ouvinte para compreender o significado do seu proferimento, com o conhecimento partilhado deles dos fatos de fundamento conversacional e com a habilidade do ouvinte de fazer inferências, quando o falante respeita tais máximas. $\mathrm{O}$ que acontece quando um falante produz um ato de fala indireto ou não literal é que

Quando um falante usa uma máxima e o ouvinte reconhece os fatos de base conversacional que o falante tem em mente, o ouvinte faz uma inferência e chega à conclusão que o falante tenciona levá-lo a entender que ele realiza um ato de fala secundário não literal em adição ao ato ilocucionário primário. (VANDERVEKEN, 1993, p. 376, tradução nossa)

É importante ressaltar que, embora o falante tencione levar o ouvinte a "entender que ele realiza um ato de fala secundário não literal em adição ao ato ilocucionário primário”, o que acontece, na realidade, é o inverso, ou seja, o ouvinte percebe o ato indireto ou não literal como a realização primária do ato. Mari (2011) esquematiza da seguinte forma a questão:

\begin{tabular}{|l|l|}
\hline \multicolumn{2}{|c|}{ Relação entre enunciado proferido e significado } \\
\hline ATO $_{\text {DIRETO }}$ & $\begin{array}{l}\text { O locutor executa primariamente o ato expresso no significado convencionado no enunciado } \\
\left(\text { Edo }_{\mathrm{N}} \rightarrow \mathrm{So}_{\mathrm{N}}\right)\end{array}$ \\
\hline ATO $_{\text {INDIRETO }}$ & $\begin{array}{l}\text { O locutor executa primariamente o ato expresso no significado intencionado pelo locutor no } \\
\text { enunciado (Edo }\end{array} \rightarrow \mathrm{So}_{\mathrm{NN}}$ ) ou (Edo $\left.{ }_{\mathrm{NN}} \rightarrow \mathrm{So}_{\mathrm{NN}}\right)$
\end{tabular}
Quadro 4 - relação entre enunciado proferido e significado. Fonte: Mari, 2011.

Existe, então, em relação ao significado natural ( $\left.\mathrm{So}_{\mathrm{N}}\right)$, uma maior ou menor intervenção do locutor sobre o significado de um enunciado, intervenção que parece ter uma dependência direta das condições preparatórias, ou seja, dos papéis que um locutor exerce numa dada situação comunicativa.

É interessante notar, em relação ao comportamento dos atos indiretos, que, embora se vinculem ao domínio da intencionalidade, eles podem vir a se tornar construções idiomáticas padronizadas em uma determinada sociedade, obedecendo, portanto, a convenções que garantem as condições de sucesso e de satisfação na realização do ato. Um exemplo disso na nossa língua seria o uso de diretivos no modo pergunta com o objetivo de pedir algo: "Você sabe onde fica a casa do Paulo?". Aqui, a pergunta funciona como um pedido de informação e, por isso, a não ser em circunstâncias muito específicas, o locutor deseja uma resposta que vá além de um "Sim" ou "Não". 
Essa é uma construção já cristalizada em nossas trocas verbais cotidianas, pois é um ato indireto que já é entendido como se fosse direto pelos indivíduos em nossa sociedade, ou seja, um ato deixou de se submeter a uma convenção de uso e passou a submeter-se a uma convenção linguística; tornou-se uma convenção de linguagem. Foi Morgan (1991) quem apresentou uma definição do que seriam as "convenções de uso" em oposição às "convenções linguísticas":

[...] estou propondo que existam pelo menos duas formas de convenção distintas envolvidas nos atos de fala: [...] A primeira, convenções lingüísticas [sic], é constitutiva da linguagem, ao menos em parte. A segunda, convenções de uso, é uma questão cultural, mas não uma questão lingüística [sic] própria. (MORGAN, 1991, p. 247, tradução nossa)

As "convenções de uso" contêm três tipos de elementos: ocasião, propósito e meios. Morgan explica que, quando as relações entre propósito e meios ou entre ocasião e propósito se torna obscura, a forma linguística se torna mais arbitrária e seu uso se torna dependente de uma "convenção de linguagem”. Enfim, uma "convenção de uso" pode vir a se tornar uma "convenção de linguagem", dependendo da natureza das relações estabelecidas entre esses elementos que compõem as "convenções de uso".

\section{UMA PROPOSTA DE ANÁLISE}

A narrativa utilizada como corpus deste trabalho foi produzida a partir da disputa entre as equipes Corinthians e Santo André, no dia 15 de março de 2009, no Estádio Bruno José Daniel em Santo André, e fez parte da 14a rodada do Campeonato Paulista de 2009. Foram gravadas e transcritas transmissões realizadas pela Rádio Globo e Rádio Eldorado/ESPN, sendo que, para a análise, efetuamos um recorte de trechos que compõem o $2^{\circ}$ tempo da partida.

Apresentamos, inicialmente, uma análise dos atos de fala indiretos presentes em ambas as narrativas. Na coluna dos "Atos de fala" trazemos atos indiretos realizados por Oscar Ulisses, cuja função enunciativa é ser narrador da partida. Como narrador e gerenciador dos turnos na construção dessa narrativa, ele procura estabelecer um ambiente de interação com os comentaristas, repórteres e plantonistas que também compõem a cena enunciativa. Nesse primeiro momento, desejamos ressaltar os atos de fala que ele produz nessa troca de turno.

\begin{tabular}{|c|c|c|}
\hline \multicolumn{3}{|c|}{ Atos de Fala produzidos na Rádio Globo: domínio das convenções e das intenções } \\
\hline Ato de fala & D: convenções & D: intenções \\
\hline "Neneca pega. Oi, Paschoal!" & $\begin{array}{l}\text { П : expressivo } \\
\mu \text { : saudação } \\
\Theta: \text { locutor tem conhecimento de } \\
\text { quem é Paschoal e de que ele é } \\
\text { seu interlocutor. } \\
\Sigma \text { : locutor em relação hierárquica } \\
\text { superior ao alocutário } \\
\text { (gerenciador dos turnos de fala). } \\
\Psi: \text { locutor acredita que deve } \\
\text { manter um diálogo com o } \\
\text { comentarista }\end{array}$ & $\begin{array}{l}\Pi \text { : diretivo } \\
\mu \text { : interpelação } \\
\Theta: \text { disponibilidade do } \\
\text { alocutário para opinar } \\
\text { sobre o jogo. } \\
\Sigma: \text { locutor em relação } \\
\text { hierárquica superior ao } \\
\text { alocutário (gerenciador dos } \\
\text { turnos de fala). } \\
\Psi: \text { locutor acredita que o } \\
\text { comentarista deva trazer } \\
\text { algo de relevante para a } \\
\text { narrativa. }\end{array}$ \\
\hline Ato de Fala & D: convenções & D: intenções \\
\hline $\begin{array}{l}\text { "Gol no Campeonato, gol na } \\
\text { Globo!" }\end{array}$ & $\begin{array}{l}\Pi \text { : assertivo } \\
\mu \text { : afirmação } \\
\Theta \text { : forma exclamativa } \\
\Sigma: \text { locutor, enquanto narrador, } \\
\text { informa sobre fatos relativos ao } \\
\text { Campeonato. } \\
\Psi \text { : locutor acredita que deve } \\
\text { informar fatos sobre o } \\
\text { Campeonato. }\end{array}$ & $\begin{array}{l}\Pi \text { : diretivo } \\
\mu \text { : interpelação } \\
\text { (metonímica) } \\
\Theta: \text { disponibilidade de um } \\
\text { interlocutor que informe } \\
\text { sobre o lance. } \\
\Sigma: \text { locutor em relação } \\
\text { hierárquica superior ao } \\
\text { alocutário (gerenciador dos }\end{array}$ \\
\hline
\end{tabular}




\begin{tabular}{|c|c|c|}
\hline & & $\begin{array}{l}\text { turnos de fala). } \\
\Psi \text { : locutor acredita que o } \\
\text { comentarista deva trazer } \\
\text { algo de relevante para a } \\
\text { narrativa. }\end{array}$ \\
\hline Ato de Fala & D: convenções & D: intenções \\
\hline $\begin{array}{l}\text { "Plantão Globo, o locutor é } \\
\text { show!" }\end{array}$ & 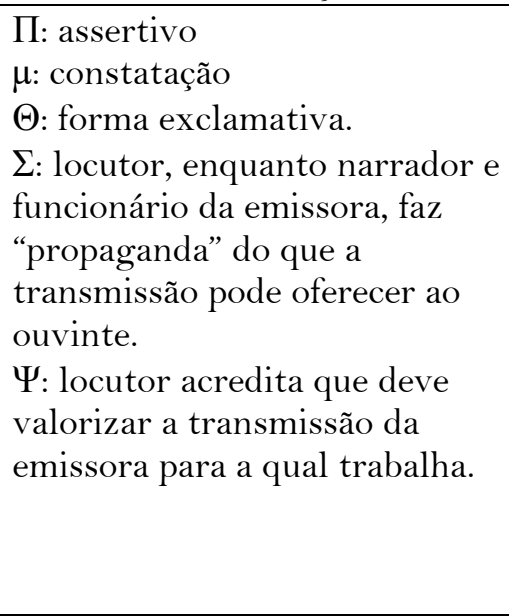 & $\begin{array}{l}\text { П: diretivo } \\
\mu \text { : interpelação } \\
\text { (metonímica) } \\
\Theta: \text { disponibilidade de um } \\
\text { interlocutor que informe } \\
\text { sobre o plantão. } \\
\Sigma: \text { locutor em relação } \\
\text { hierárquica superior ao } \\
\text { alocutário (gerenciador dos } \\
\text { turnos de fala). } \\
\Psi \text { : locutor acredita que o } \\
\text { plantonista deva trazer algo } \\
\text { de relevante para a } \\
\text { narrativa. }\end{array}$ \\
\hline
\end{tabular}

Quadro 5 - Atos de Fala produzidos na Rádio Globo: domínio das convenções e das intenções.

É importante dizer que ao longo da narrativa do $2^{\circ}$ tempo de jogo também foram identificados diversos atos diretos, em que o narrador, ao passar a palavra para seus interlocutores, deseja que estes reconheçam que tais atos significam o que o locutor quer significar literalmente com esse proferimento e, portanto, que estes reconheçam as regras que regem a produção daquelas sentenças.

Observando os atos indiretos acima, objeto deste trabalho, notamos que eles apresentam duas forças ilocucionárias distintas, uma no domínio das convenções e outra no domínio das intenções. Assim, vemos que o mesmo ato adquire um significado além do que aparenta ter em sua superfície.

Inseridos em uma circunstância específica de interação, tais atos demonstram uma intencionalidade inerente à sua produção a qual, conforme abordaremos mais à frente, possui a seguinte estrutura: Loc/INT1 versus Aloc/INT1, isto é, o alocutário percebe e compreende o ato de fala do narrador como dotado de intencionalidade - seja ela de que o comentarista ou o plantonista deva trazer algo de relevante para a narrativa, assumindo o turno de fala, comentando ou informando algo. Vejamos a seguir os atos produzidos pelo narrador da Rádio Eldorado/ESPN, Paulo Soares, o "Amigão”.

\begin{tabular}{|c|c|c|}
\hline \multicolumn{3}{|c|}{ Atos de Fala produzidos na Rádio Eldorado/ESPN: domínio das convenções e das intenções } \\
\hline Ato de Fala & D: convenções & D: intenções \\
\hline $\begin{array}{l}\text { "Tiro de meta pro } \\
\text { Corinthians e quase } \\
\text { quase Escobar espeta } \\
\text { o primeiro do jogo, } \\
\text { Loredo!!" }\end{array}$ & $\begin{array}{l}\Pi \text { : assertivo } \\
\mu \text { : constatação } \\
\Theta: \text { locutor tem conhecimento de que } \\
\text { o repórter é seu interlocutor } \\
\Sigma: \text { locutor em relação hierárquica } \\
\text { superior ao alocutário (gerenciador } \\
\text { dos turnos de fala). } \\
\Psi: \text { locutor acredita que deve } \\
\text { informar fatos sobre o jogo. }\end{array}$ & $\begin{array}{l}\Pi \text { : diretivo } \\
\mu \text { : interpelação } \\
\Theta: \text { conhecimento de que o repórter } \\
\text { tem autoridade para esclarecer } \\
\text { dúvidas sobre o lance. } \\
\Sigma \text { : locutor em relação hierárquica } \\
\text { superior ao alocutário (gerenciador } \\
\text { dos turnos de fala). } \\
\Psi: \text { locutor acredita que o repórter } \\
\text { deve trazer algo de relevante para a } \\
\text { narrativa. }\end{array}$ \\
\hline Ato de Fala & D: convenções & D: intenções \\
\hline $\begin{array}{l}\text { "Oi, Conrado Giullieti! } \\
\text { Pacaembu, Conrado!" }\end{array}$ & $\begin{array}{l}\text { П: expressivo } \\
\mu \text { : contato }\end{array}$ & $\begin{array}{l}\text { П: diretivo } \\
\mu: \text { interpelação }\end{array}$ \\
\hline
\end{tabular}




\begin{tabular}{|c|c|c|}
\hline & $\begin{array}{l}\Theta: \text { locutor tem conhecimento de que } \\
\text { o repórter é seu interlocutor } \\
\Sigma \text { : locutor em relação hierárquica } \\
\text { superior ao alocutário (gerenciador } \\
\text { dos turnos de fala). } \\
\Psi \text { : locutor acredita que o plantonista } \\
\text { deve trazer algo de relevante para a } \\
\text { narrativa. }\end{array}$ & $\begin{array}{l}\Theta \text { : locutor tem conhecimento de que } \\
\text { o plantonista tem autoridade para } \\
\text { informar sobre o Campeonato. } \\
\Sigma \text { : locutor em relação hierárquica } \\
\text { superior ao alocutário (gerenciador } \\
\text { dos turnos de fala). } \\
\Psi \text { : locutor acredita que o plantonista } \\
\text { deve trazer algo de relevante para a } \\
\text { narrativa. }\end{array}$ \\
\hline Ato de Fala & D: convenções & D: intenções \\
\hline “O gol, Marcelo:::!!!” & $\begin{array}{l}\text { П: expressivo } \\
\mu \text { : evocação } \\
\Theta: \text { conhecimento de que o } \\
\text { plantonista é seu interlocutor } \\
\Sigma \text { : locutor, enquanto narrador, } \\
\text { informa sobre fatos relativos ao } \\
\text { Campeonato. } \\
\Psi \text { : locutor acredita que deve } \\
\text { informar fatos sobre o Campeonato. }\end{array}$ & $\begin{array}{l}\text { П: diretivo } \\
\mu \text { : interpelação } \\
\Theta: \text { locutor tem conhecimento de que } \\
\text { o plantonista tem autoridade para } \\
\text { informar sobre o Campeonato. } \\
\Sigma \text { : locutor em relação hierárquica } \\
\text { superior ao alocutário (gerenciador } \\
\text { dos turnos de fala). } \\
\Psi \text { : locutor acredita que o plantonista } \\
\text { deve trazer algo de relevante para a } \\
\text { narrativa. }\end{array}$ \\
\hline Ato de Fala & D: convenções & D: intenções \\
\hline $\begin{array}{l}\text { "Morumbi chama! } \\
\text { Eduardo Afonso, São } \\
\text { Paulo e Marília!! Já já } \\
\text { o jogo, Edu!!!" }\end{array}$ & $\begin{array}{l}\text { П: diretivo } \\
\mu \text { : evocação } \\
\Theta: \text { conhecimento de que o } \\
\text { plantonista é seu interlocutor. } \\
\Sigma: \text { locutor, enquanto narrador, } \\
\text { informa sobre fatos relativos ao } \\
\text { Campeonato. } \\
\Psi \text { : locutor acredita que deve } \\
\text { informar fatos sobre o Campeonato. }\end{array}$ & $\begin{array}{l}\text { П: diretivo } \\
\mu \text { : permissão } \\
\Theta: \text { locutor tem conhecimento de que } \\
\text { o plantonista tem autoridade para } \\
\text { informar sobre o Campeonato. } \\
\Sigma \text { : locutor em relação hierárquica } \\
\text { superior ao alocutário (gerenciador } \\
\text { dos turnos de fala). } \\
\Psi \text { : locutor acredita que o plantonista } \\
\text { deve trazer algo de relevante para a } \\
\text { narrativa. }\end{array}$ \\
\hline
\end{tabular}

Quadro 6 - Atos de Fala produzidos na Rádio Eldorado/ESPN: domínio das convenções e das intenções.

Durante a narração de Paulo Soares, em especial do $2^{\circ}$ tempo de jogo, ele realiza tanto atos diretos, quanto indiretos no momento da troca de turno, embora neste caso haja um predomínio dos indiretos, enquanto na Rádio Globo, os atos diretos foram mais recorrentes. Isso se deve, principalmente, ao estilo que cada narrador escolhe para evocar os demais interlocutores. $\mathrm{O}$ uso dos atos indiretos também parece funcionar como uma economia de linguagem, já que no rádio os locutores devem informar o máximo que puderem em um curto espaço de tempo.

Os atos indiretos produzidos pelo narrador apresentam, assim como na narração da Rádio Globo, mudança em relação ao ponto e ao modo conforme os analisamos no domínio das convenções ou das intenções. Por isso, também nesses casos percebemos que um mesmo ato pode apresentar um significado que se encontra além do que é recuperado na superfície linguística.

O narrador e seus interlocutores se inserem aqui em uma situação específica de interação, cuja relação em termos de intencionalidade apresenta a mesma estrutura da primeira narrativa: Loc/INT1 versus Aloc/INT1, uma vez que os interlocutores reconhecem as intenções do narrador - significar algo mais do que o que deseja significar ao proferir um ato $\mathrm{F}(\mathrm{P})$.

Isso é possível, em ambas as narrativas, porque os interlocutores demonstram ter habilidade para entender a natureza do ato de fala literal, compartilham certos fatos implicados na conversação - o papel que cada um assume, a própria narrativa que é racionalizada no discurso, etc - e a capacidade de realizar inferências - 
perceber que um ato indireto que possui a forma de um assertivo, na verdade, realiza um ato diretivo, que revela a intenção do narrador de trocar o turno com o comentarista, o repórter ou o plantonista.

Verificamos que, no domínio da intencionalidade, onde se inscreveram os atos indiretos, não é possível estabelecer padrões que nos permitam defini-los como tal, principalmente se analisarmos tais atos fora de seu suporte original - o rádio. Como já foi apontado por Mari (2001), percebemos no caso do corpus em questão, que a entonação, as modulações de voz, desempenhadas pelos narradores é que nos levam, em especial, a conferir a tais atos o estatuto de indiretos, é que nos conduz a um significado além do que se apresenta na superfície do enunciado.

Observamos também que o fato de o narrador da Rádio Globo demonstrar uma preferência pelos atos diretos, revela um locutor que parece não se "arriscar" a significar um ato intencionalmente - seja devido a um caráter mais conservador da emissora ou do modo de narrar do narrador, ou ainda como uma estratégia para alcançar uma maior audiência.

Destacaremos agora, com maior especificidade, o aspecto interativo das narrativas, apresentando uma articulação entre a teoria dos atos de fala e a teoria da conversação. Os excertos analisados seguem a mesma ordem acima, porém, para os objetivos do momento, trazemos os atos produzidos pelos interlocutores, resultantes dos atos proferidos pelo narrador. Seguem, abaixo, os trechos extraídos da narrativa da Rádio Globo.

\begin{tabular}{|l|}
\hline \multicolumn{1}{|c|}{ Análise da interação na Rádio Globo (1) } \\
\hline $\begin{array}{l}\text { OU: “Pega mal... domina mal, Lulinha. Bola fora para o goleiro. […] } \\
\text { Neneca pega. Oi, Paschoal!” } \\
\text { OP: “Normal!" }\end{array}$ \\
\hline PROCESSO INFERENCIAL \\
Ação discursiva de OP: emitir opinião sobre desempenho de jogadores. \\
So do Edo > Ato direto = $\pi$ : assertivo / $\mu$ : afirmação \\
Máxima da relevância: é pertinente que o locutor expresse sua opinião, considerando o fato de que \\
conhece as condições preparatórias para fazê-lo.
\end{tabular}

Quadro 7 - Análise da interação na Rádio Globo (1).

Percebemos, nessa troca verbal, que o interlocutor de Oscar Ulisses, o comentarista Osvaldo Paschoal, percebe a intenção do narrador presente na enunciação do ato "Oi, Paschoal!". Ele compreende que o significado do ato ultrapassa os limites do significado literal desse mesmo proferimento. Ao realizar um ato direto assertivo, ele se utiliza da máxima da relevância, ou seja, enunciando o que é relevante para alguém que possui como condições preparatórias o papel de comentarista e, principalmente, de interlocutor de Oscar Ulisses.

Análise da interação na Rádio Globo (2)

OU: "Gol no Campeonato, gol na Globo!"

M: Lá no Rio de Janeiro, festa lá pro Fluminense, o Fred, que está estreando, marcou de cabeça. Agora, Fluminense 1, Macaé também 1!"

PROCESSO INFERENCIAL

Ação discursiva de M: informar dados de outros campeonatos estaduais.

So do Edo $>$ Ato direto $=\pi$ : assertivo $/ \mu$ : afirmação

Máxima da qualidade: existem evidências de que seu proferimento assegure qualitativamente a sua realização como verdadeira/veraz.

$$
\text { Quadro } 8 \text { - Análise da interação na Rádio Globo (2). }
$$

Notamos que o plantonista Márcio também percebe a intenção do narrador presente na enunciação do ato "Gol no Campeonato, gol na Globo!". Do mesmo modo que Paschoal, ele compreende que o significado do ato vai além dos limites do significado literal desse mesmo proferimento. Ao realizar um ato direto assertivo, ele se utiliza da máxima da qualidade, ou seja, o narrador lhe permite assumir o turno, pois reconhece que, por estar numa condição de plantonista terá acesso a diversas informações de fontes 
confiáveis ou até mesmo por estar presente no local de onde fala. Assim, é possível que ele assegure o proferimento do seu ato como uma informação verdadeira, de qualidade.

\begin{tabular}{|c|}
\hline Análise da interação na Rádio Globo (3) \\
\hline $\begin{array}{l}\text { OU: "Plantão Globo, o locutor é show!" } \\
\text { M: "Guarani e Oeste, às } 18 \text { e 10, lá em Campinas. Lá no Rio de Janeiro, o Vasco da Gama vence o } \\
\text { Boa Vista e o Macaé vence o Fluminense, Oscar!" }\end{array}$ \\
\hline $\begin{array}{l}\text { PROCESSO INFERENCIAL } 1 \\
\text { Ação discursiva de M: informar dados sobre outras partidas do Campeonato Paulista e dos } \\
\text { campeonatos estaduais. } \\
\text { So do Edo } 1>\text { Ato direto }=\pi \text { : assertivo / } \mu \text { : afirmação } \\
\text { So do Edo2 > Ato direto = } \pi \text { : assertivo / } \mu \text { : afirmação } \\
\text { Máxima da qualidade: existem evidências de que seu proferimento assegure qualitativamente a sua } \\
\text { realização como verdadeira/veraz. } \\
\text { PROCESSO INFERENCIAL } 2 \\
\text { Ação discursiva de M: informar dados sobre outras partidas do Campeonato Paulista e dos } \\
\text { campeonatos estaduais. } \\
\text { Edo } \rightarrow \text { SonN, logo um So do locutor } \\
\text { So do Edo2 > Ato indireto = } \pi \text { : diretivo / } \mu \text { : interpelação } \\
\text { Máxima da quantidade: seria o bastante o locutor dizer "Oscar!" esperando que o alocutário fosse } \\
\text { capaz de inferir que se trata de uma interpelação e validar o ato como tal. }\end{array}$ \\
\hline
\end{tabular}

$$
\text { Quadro } 9 \text { - Análise da interação na Rádio Globo (3). }
$$

Neste trecho, verificamos que, num primeiro momento o plantonista Márcio percebe a intenção do narrador presente na enunciação do ato "Plantão Globo, o locutor é show!". Há uma compreensão de que o ato significa algo mais do que parece enunciar, o que é comprovado pelo proferimento de um ato direto assertivo e pela submissão deste à máxima da qualidade, ao responder ao narrador.

Contudo, quando o plantonista diz "Lá no Rio de Janeiro, o Vasco da Gama vence o Boa Vista e o Macaé vence o Fluminense, Oscar!", ele parece imprimir ao enunciado natural um significado não natural, apresentando além do significado linguístico um significado do locutor. Ele não profere “[...] Oscar!” apenas para mostrar para o ouvinte que o narrador é seu interlocutor, mas como um "sinal" de que o turno deve ser retomado por ele. Desse modo, o plantonista lança mão da máxima da quantidade, já que seria suficiente o locutor dizer "Oscar!" para que o narrador fosse capaz de inferir que se trata de uma interpelação e validar o ato como tal.

Passemos à análise da interação na Rádio ESPN/Eldorado.

\begin{tabular}{|l|}
\hline Análise da interação na Rádio Eldorado/ESPN (1) \\
\hline PS: “Tiro de meta pro Corinthians e quase quase Escobar espeta o primeiro do jogo, Loredo!!” \\
SL: “Com 10 segundos! Pra já assustar o goleiro Felipe!! Voou na bola, ela passou muito perto pelo \\
lado esquerdo! Tiro de meta, Corinthians, e o... a maca tá dando problema lá... hein, Amigão? \\
\hline PROCESSO INFERENCIAL 1 \\
Ação discursiva de SL: informar dados do jogo e dados de bastidores. \\
So do Edo 1 > Ato direto $=\pi:$ assertivo / $\mu$ : afirmação \\
So do Edo2 > Ato direto $=\pi:$ expressivo/ $\mu$ : evocação \\
Máxima da qualidade: existem evidências de que seu proferimento assegure qualitativamente a sua \\
realização como verdadeira/veraz. \\
PROCESSO INFERENCIAL 2 \\
Ação discursiva de SL: informar dados do jogo e dados de bastidores. \\
EdoNn $\rightarrow$ SonN , logo um significado do locutor \\
So do Edo2 > Ato indireto = $\pi:$ diretivo/ $\mu$ : interpelação > EP: deboche \\
Máxima da quantidade: seria o bastante o locutor dizer “Amigão?” esperando que o alocutário fosse \\
capaz de inferir que se trata de uma interpelação e validar o ato como tal. \\
\hline
\end{tabular}

Quadro 10 - Análise da interação na Rádio Eldorado/ESPN (1). 
Verificamos que, inicialmente, o repórter Sérgio Loredo percebe a intenção do narrador presente na enunciação do ato “[...] quase Escobar espeta o primeiro do jogo, Loredo!!”. Ele reconhece que o ato tem um significado além do que parece apresentar. Isso se comprova pelo fato de o repórter enunciar "Com 10 segundos! Pra já assustar o goleiro Felipe!! Voou na bola, ela passou muito perto pelo lado esquerdo! Tiro de meta, Corinthians [...]”, um ato direto assertivo. Ele se submete, dessa forma, à máxima da qualidade, já que as condições preparatórias de seu ato permitem que ele desempenhe o papel de alguém que possui as informações mais atualizadas e confiáveis, até mesmo que o narrador, pois essa é a sua função na narrativa.

Contudo, quando o repórter diz “e o... a maca tá dando problema lá... hein, Amigão?”, ele parece atribuir a este enunciado não natural um significado não natural, apresentando além do significado linguístico um significado do locutor. Ele não o profere apenas para evocar o narrador, mas para passar-lhe o turno de fala, interpelando-o para que se pronuncie a respeito do acontecimento "inusitado" em campo. Além disso, o modo como enuncia o seu proferimento, em termos de entonação, causa um efeito perlocucional de deboche pelo fato de a maca estar posicionada em lugar indevido durante a partida, o que parece demonstrar falta de organização do evento.

O repórter se utiliza da máxima da quantidade, já que seria suficiente o locutor dizer “[...] hein, Amigão?” para que o narrador fosse capaz de inferir que se trata de uma interpelação e validar o ato como tal.

\begin{tabular}{|l|}
\hline Análise da interação na Rádio Eldorado/ESPN (2) \\
\hline PS: “Oi Conrado Giullieti! Pacaembu Conrado!" \\
CG: “Temos alguns segundos só pra registrar a chegada do Santos e o Neymar que vai fazer o \\
primeiro jogo dele como titular?” \\
\hline PROCESSO INFERENCIAL \\
Ação discursiva de CG: informar dados de bastidores de outros campeonatos estaduais. \\
So do Edo > Ato direto = $\pi$ : diretivo/ $\mu$ : pergunta \\
Máxima da relevância: é pertinente que o locutor pergunte se possui permissão para realizar uma \\
ação x, considerando o fato de que conhece as condições preparatórias para fazê-la.
\end{tabular}

Quadro 11 - Análise da interação na Rádio Eldorado/ESPN (2).

Neste excerto, o repórter Conrado Giullieti percebe a intenção do narrador presente na enunciação do ato "Oi Conrado Giullieti! Pacaembu Conrado!". Ele demonstra compreender que o significado do ato excede os limites do significado literal desse mesmo proferimento. Ao realizar um ato direto diretivo, ele submete seu enunciado à máxima da relevância, pois é pertinente que, enquanto repórter, pergunte se possui permissão para realizar uma determinada ação discursiva, considerando que conhece as condições preparatórias para fazê-la.

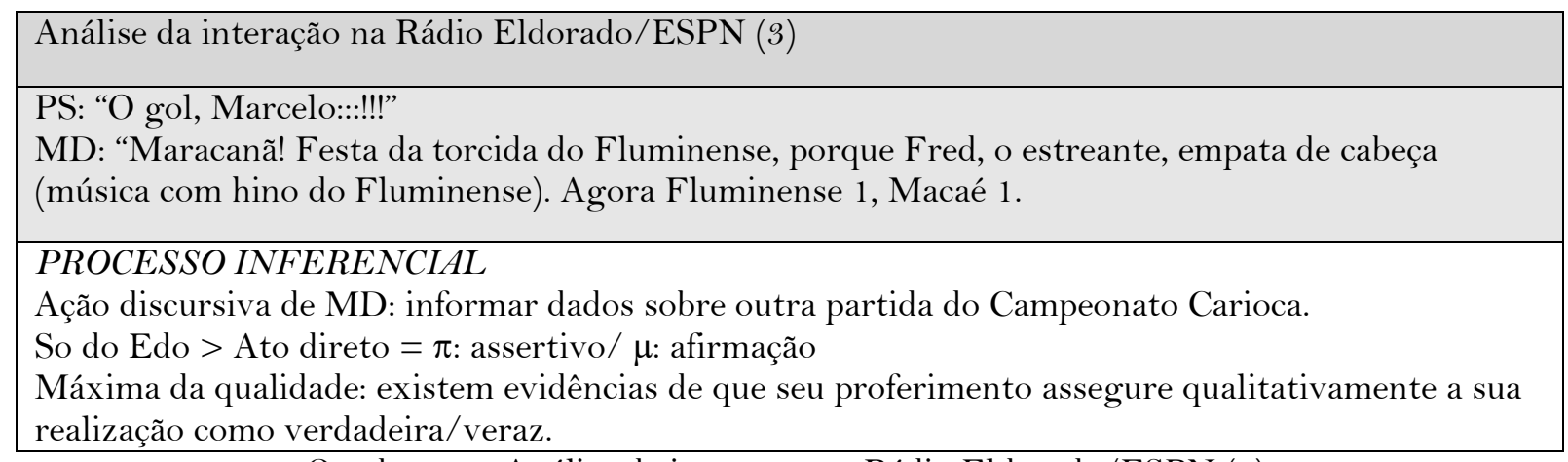
Quadro 12 - Análise da interação na Rádio Eldorado/ESPN (3).

O plantonista Marcelo Dilalo, assim como Giullieti, percebe a intenção do narrador presente na enunciação do ato "O gol, Marcelo::!!!". Ele demonstra compreender que o significado do ato extrapola o significado literal desse mesmo proferimento. Ao realizar um ato direto assertivo, ele se utiliza da máxima da qualidade, pois por apresentar como condições preparatórias o papel de plantonista, é crível que o seu ato assegure qualitativamente a sua realização como verdadeira. 


\begin{tabular}{|l|}
\hline Análise da interação na Rádio Eldorado/ESPN (4) \\
\hline PS: “Morumbi chama! Eduardo Afonso, São Paulo e Marília!! Já, já o jogo, Edu!!!” \\
EA: “As duas equipes já escaladas por aqui, Amigão!” \\
\hline PROCESSO INFERENCIAL 1 \\
Ação discursiva de EA: informar dados sobre outra partida do Campeonato Paulista. \\
So do Edo > Ato direto = $\pi$ : assertivo / $\mu$ : constatação \\
Máxima da qualidade: existem evidências de que seu proferimento assegure qualitativamente a sua \\
realização como verdadeira/veraz. \\
PROCESSO INFERENCIAL 2 \\
Ação discursiva de EA: informar dados sobre outra partida do Campeonato Paulista. \\
EdoNn $\rightarrow$ SonN, logo um So do locutor \\
So do Edo > Ato indireto = $\pi$ : diretivo/ $\mu$ : interpelação \\
Máxima da quantidade: seria o bastante o locutor dizer “Amigão?” esperando que o alocutário fosse \\
capaz de inferir que se trata de uma interpelação e validar o ato como tal. \\
\hline
\end{tabular}

Quadro 13 - Análise da interação na Rádio Eldorado/ESPN (4).

A princípio, o plantonista Eduardo Afonso reconhece a intenção do narrador na enunciação do ato “[...] Já, já o jogo, Edu!!!”". Ele percebe que o ato tem um significado além do que parece apresentar. Isso se comprova pelo fato de o plantonista enunciar "As duas equipes já escaladas por aqui, Amigão!", um ato direto assertivo, que se submete à máxima da qualidade, pois as condições preparatórias de seu ato permitem que ele exerça o papel de alguém que possui as informações mais atualizadas e confiáveis.

No entanto, quando o plantonista profere “As duas equipes já escaladas por aqui, Amigão!", ele parece conferir a este enunciado não natural um significado não natural, apresentando além do significado linguístico um significado do locutor. Além de informar ao narrador que as duas equipes estão escaladas, ele deseja, com esse ato, passar-lhe o turno de fala. O repórter se utiliza da máxima da quantidade, já que seria suficiente o locutor dizer “[...] Amigão?" para que o narrador fosse capaz de inferir que se trata de uma interpelação e validar o ato como tal.

Retomando tudo o que foi dito, no que tange aos atos indiretos realizados pelos interlocutores, podemos dizer que estes compreendem os atos de fala produzidos pelos narradores como se tais atos apresentassem um significado convencional, ainda que eles possuíssem, em grande parte (como é o caso a Rádio Eldorado/ESPN), um significado intencional.

Isso se deve ao fato de que os critérios que levam os interlocutores a interpretar tais atos como convencionais não são apenas de natureza linguística, mas dependentes do processo inferencial (uso das máximas de Grice).

Há muitas expressões de uma língua que, além das convenções linguísticas e convenções sobre o uso de expressões linguísticas, estão submetidas também a convenções de ordem cultural, que expressam convenções sobre o seu uso dentro de uma comunidade. (MARI, 2011, p. 5)

\section{CONCLUSÃO}

Finalizamos este artigo dizendo que muitos atos realizados pelos interlocutores que co-constroem uma narração esportiva de futebol, embora se apresentem como indiretos e, por isso, pertencem ao domínio das intenções, têm adquirido um uso convencional, ou seja, têm abandonado o estatuto de convenções de uso e se tornado convenções linguísticas. Isso é verificado pelo fato de os ouvintes já reconhecerem, diretamente, nessas formas apontadas em nossas análises, o significado não literal como o significado literal. Assim, no momento da compreensão de um ato, tanto o narrador, os comentaristas, os repórteres e os plantonistas quanto os ouvintes reconhecem tais atos indiretos como convencionais.

Procuramos demonstrar também que a Pragmática, por meio da Teoria dos Atos de Fala e seus desdobramentos, pode fornecer instrumentos relevantes de análise que auxiliam na compreensão do funcionamento dos discursos e das funções discursivas que narrador e os coparticipantes desempenham na interação que estabelecem durante a narração de uma partida de futebol. Sabemos que há muitos outros aspectos implicados nessa atividade discursiva; no entanto, acreditamos que essa perspectiva analítica pode, 
junto a outros quadros teóricos, colaborar em nossa busca por respostas a muitas indagações relativas à produção e recepção do discurso produzido nesse gênero discursivo.

Muito ainda há que se estudar, sob um viés linguístico-discursivo, acerca do discurso produzido nas narrações esportivas de futebol, tanto no rádio como na televisão, contudo, esperamos ter colaborado em parte para uma melhor compreensão desse gênero, que passou a circular em nossa sociedade com o advento do rádio, a partir do estudo dos atos de fala nele produzidos.

\section{REFERÊNCIAS}

AUSTIN, J. L. Quando dizer é fazer: palavras e ação. Porto Alegre: Artes Médicas, 1990.

GRICE, H. P. Lógica e conversação. In: DASCAL, M. Fundamentos metodológicos da lingüística. Campinas: Edição particular, 1982.

MARI, H. A teoria dos atos de fala entre convenções e intenções. In: MENDES, E. A. de M., OLIVEIRA, P. M., BENN-IBLER, V. O novo milênio: interfaces lingüísticas e literárias. Belo Horizonte: UFMG/FALE, 2001.

. Anotações de aula. Seminário de Estudos Avançados: Teoria dos Atos de Fala. Programa de PósGraduação em Letras. Pontifícia Universidade Católica de Minas Gerais, 2011.

MORGAN, J. L. Two types of convention in indirect speech acts. In: DAVIS, S. Pragmatics: a reader. v. 14. New York, Orford: Oxford University Press, 1991.

RÉCANATI, F. Enoncés performatifs et actes illocutionnaires: le point de vue conventionaliste. In: RÉCANATI, F. Les enoncés performatifs. Paris: Minuit, 1981.

SANTOS, C. A. R. A narração esportiva de futebol: análise discursiva de um fenômeno midiático. 2010. 181 f. Dissertação (Mestrado em Linguística e Língua Portuguesa) - Pontifícia Universidade Católica de Minas Gerais, Belo Horizonte, 2010.

SEARLE, J. Os atos de fala indiretos. In: SEARLE, J. Expressão e significado: estudos da teoria dos atos de fala. Trad. de Ana Cecília G.A. de Camargo e Ana Luiza Marcondes Garcia. São Paulo: Martins Fontes, 1995.

VANDERVEKEN, D. O que é uma força ilocucional? Tradução João Wanderley Geraldi. Cadernos de Estudos Linguísticos, Campinas, v. 9, p. 173-194, 1985.

. Non-literal speech acts and conversational maxims. In: LEPORE, E.; VAN GULICK, R. (Eds.). John Searle and his critics. New York: Blackwell,1993.

Recebido em 17/06/12. Aprovado em 21/08/12. 